\title{
Skolyoz Hastalığının Tespiti için Taşınabilir Cihaz Tasarımı
}

\author{
Ahmet Ali Süzen ${ }^{1}$, Ziya Yıldız ${ }^{2}$, Kıyas Kayaalp ${ }^{3}$, Osman Ceylan ${ }^{4}$, Emre Arabac1 ${ }^{5 *}$ \\ ${ }^{1}$ Isparta Uygulamalı Bilimler Üniversitesi, Uluborlu Selahattin Karasoy MYO., Bilgisayar Teknolojileri Bölümü, Isparta, Türkiye (ORCID: 0000-0002-5871-1652) \\ ${ }^{2}$ Isparta Uygulamalı Bilimler Üniversitesi, Uluborlu Selahattin Karasoy MYO, Terapi ve Rehabilitasyon Bölümü, Isparta, Türkiye (ORCID: 0000-0001-6057-3669) \\ ${ }^{3}$ Isparta Uygulamalı Bilimler Üniversitesi, Uluborlu Selahattin Karasoy MYO., Bilgisayar Teknolojileri Bölümü, Isparta, Türkiye (ORCID: 0000-0002-6483-1124) \\ ${ }^{4}$ Isparta Uygulamalı Bilimler Üniversitesi, Uluborlu Selahattin Karasoy MYO., Bilgisayar Teknolojileri Bölümü, Isparta, Türkiye (ORCID: 0000-0002-6060-0134) \\ ${ }^{5}$ Burdur Mehmet Akif Ersoy Üniversitesi, Bucak Emin Gülmez Teknik Bilimler MYO., Otomotiv Teknolojisi Böl., Burdur, Türkiye (ORCID: 0000-0002-6219-7246)
}

(İlk Geliş Tarihi 1 Mart 2019 ve Kabul Tarihi 23 Mart 2019)

(DOI: $10.31590 /$ ejosat.534572)

ATIF/REFERENCE: Süzen, A. A., Yıldız, Z., Kayaalp, K., Ceylan, O. \& Arabacı, E. (2019). Skolyoz Hastalığının Tespiti için Taşınabilir Cihaz Tasarımı. Avrupa Bilim ve Teknoloji Dergisi, (15), 483-490.

\section{$\ddot{O} z$}

Skolyoz omurgada meydana gelen 3 boyutlu karmaşık bir hastalıktır. Bu hastalığın sonucunda omurga kemiklerinde şekil ve diziliş bozukluğu, göğüs kafesinde eğrilik, solunum ve dolaşım sistemlerinde kısıtlılıklar oluştuğu gözlenmektedir. Skolyoz hastalığının kesin sebebi bilinmemekle beraber duruş bozukluklarının sebep olduğu düşünülmektedir. Skolyoz en sık idiopatik sebeplidir (sebebi belli olmayan) ve 10 yaş üzerindeki kız çocuklarında görülmektedir. Skolyozun erken teşhisi hastalığın seyri için önem taşımaktadır. Skolyozun kesin teşhisi için radyolojik yöntemler ve fiziksel muayene gerekmektedir. Bu hastalık hakkında toplumda yeterli bilginin olmaması erken teşhisi zorlaştırmaktadır. Bu uygulama çalışmasında Skolyoz hastalığın teşhisi için radyoaktif yayılım yapmayan, fiziksel muayenedeki yanılma payını azaltacak, portatif, hızlı ve kullanımı kolay arduino tabanlı cihaz tasarımı geliştirilmiştir. Skolyoz'un erken teşhisi için; omurganın sırtta en belirgin çıkıntıları cihazda tanımlanabilmektedir. Hedef omurganın altındaki üç omurga çıkıntısı ile üstündeki üç omurga çıkıntısı arasında bir açılanma olup olmadığını hesaplanmaktadır. Hesaplanan açılanma derecesi hangi omurgada ve kaç derecelik bir skolyoz olduğunu gösterir. Ayrıca kürek kemikleri üzerinde belirlenen referans noktaları arasındaki eğim ölçülerek skolyozun göğüs kafesine etkisi tespit edilebilmektedir.

Anahtar Kelimeler: Adam's Testi, Arduino, Cihaz Tasarımı Skolyoz.

\section{Portable Device Design for Determining of Scoliosis}

\begin{abstract}
Scoliosis is a three dimensional complex disease of the spine. As a result of this disease, shape and arrangement disorder of the vertebrae, curve in the thoracic spine, restriction in respiratory and circulatory systems are observed. Although the precise cause of scoliosis is not known, it might be caused by posture problems. Scoliosis is most frequently idiopathic (its cause is unknown) and is seen in girls older than 10 years of age. Early diagnosis of scoliosis is important for the course of the disease. For definitive diagnosis of scoliosis, radiologic methods and physical examination are required. Lack of sufficient awareness about this disease in the society makes the early diagnosis difficult. In this application study, design of a portable, rapid, and easy to use, arduino-based device which do not have radioactive emission and will reduce the margin of error in physical examination was performed. For the early diagnosis of scoliosis, the most significant protrusions of the spine can be defined in the device. The aim is to calculate whether there is an angulation between three spinal protrusions under the spine and three spinal protrusions above the spine. The calculated angulation degree shows on which vertebrae scoliosis is and its grade. Moreover, the inclination between the reference points identified on the scapula is measured to determine the effect of scoliosis on thoracic cage.
\end{abstract}

Keywords: ADAM's Test, Arduino, Device Design, Scoliosis.

\footnotetext{
* Sorumlu Yazar: Burdur Mehmet Akif Ersoy Üniversitesi, Bucak Emin Gülmez Teknik Bilimler MYO., Otomotiv Teknolojisi Böl., Burdur, Türkiye, ORCID: 0000-0002-6219-7246, earabaci@mehmetakif.edu.tr
} 


\section{Giriş}

Skolyoz, toplumda yaygın olarak görülen bir omurga eğriliği hastalıktır (Oxborrow, 2000). Skolyoz, omurganın dışa kayma rotasyonun da eşlik ettiği üç boyutlu omurga bozukluğudur. Bir başka deyişle omurganın ön ve arka radyolojik görüntülemede 10 derecenin üstündeki eğrilikler skolyoz olarak tanımlanır (Trobisch ve ark., 2010). Skolyozun en yaygın tipi gelişmekte olan bireylerde görülen sebebi belli olmayan skolyozdur. Yapılan araştırmalarda bu hastalığı sebebi net olarak belirtilmemektedir. Bu hastalık ile ilgili ülkemizde kapsamlı bir çalışma yapılmadığı görülmekle beraber, hastalığı \%0,2 ile \% 4 arasından olduğu tahmin edilmektedir. Hastalığın yaş dağılımına bakıldığı zaman 10-16 yaş arası çocuklarda daha çok görüldüğü bilinmektedir (Yaman ve Dalbayrak, 2014).

Skolyoz tanısının net konulabilmesi için ayrıntılı bir hikâyenin alınması, klinik ve radyolojik testlerinin yapılması gerekmektedir. Gelişme aşamasındaki bireyde saptanan skolyoz tanısı, ilerleyici olarak düşünülüp uzmanlar tarafından kontrol edilmelidir. Fiziksel muayenede; omurga rotasyonunu anlamak için ADAM'ın öne eğilme testi kullanılır. Dışa kayma oranını saptamak için iki omuzun yükseklik farkı ölçülür (Trobish ve ark., 2010). Omurga kemiklerinin ana çıkıntısının işaretlemesi ile açısal eğim varlığı değerlendirilir. Kesin tanı ayakta çekilen radyolojik görüntülerde Cobb açısının hesaplanması ile oluşturulur (Yılmaz ve ark., 2012).

$\mathrm{Bu}$ çalışmada skolyoz hastalığın tespitinin pratik ve güvenli bir şekilde yapılmasını sağlayan arduino temelli cihaz geliştirilmiştir. Hastalığın tespiti için bireyin omuz, sırt ve bel bölgelerinde belirlenen noktalarda 3 farklı ölçüm sonucu kullanılmaktadır. Cihaz tasarımında belirlenen bölgelerdeki koordinatların alınması için jel ped içerisine yerleştirilen XYZ konum algılayıcıları kullanılır. Algılayıcılardan alınan konum verileri matematiksel eşitlikler ile arduino geliştirme kartında işlenerek, istenilen açılar çıkartılır. Elde edilen veriler uzman tarafından yorumlanarak hastalı̆̆ın teşhisi konulmaktadır.

\section{Materyal ve Metot}

\subsection{Skolyoz}

Skolyoz, omurganın dışa kayma rotasyonunun eşlik ettiği, kas ve kemik dokularda hasar oluşturan üç boyutlu bir hastalıktır. Şekil 1'de normal birey ile skolyoz hastasına ait omurga görünümü verilmiştir. Bu hastalığın teşhisinin konulması için fiziksel muayene ve radyolojik görüntülemeye ihtiyaç duyulmaktadır. Fiziksel muayenede ADAM'ın öne eğilme testi, omuz seviyesi fark ölçüm testi ve omurga açılanma testi kullanılmaktadır. Bu fiziksel muayenelerden sonra skolyoz tanısı konulan birey, radyolojik testlere yönlendirilerek tanı kesinleştirilir (Otman ve ark., 1998).

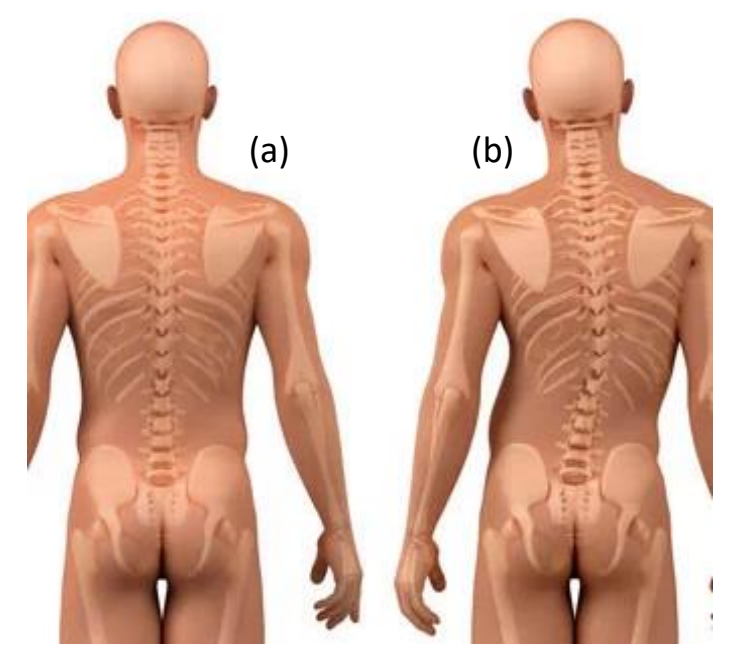

Şekil 1. (a) Normal birey ve (b) skolyoz hastası bireyin omurga görünümü

\subsubsection{ADAM'ın öne eğilme testi}

ADAM'ın öne eğilme testinde; bireyin ayakları omuz genişliğinde açık, eller her iki yanda ve rahat pozisyonda dizini kırmadan öne eğilmesi istenir. Uzman, kürek kemiklerinin belli noktalarının yere olan mesafelerini ölçer. Belirlenen noktalar arasındaki yükseklik ve açı farkını hesaplar. Bu test yöntemiyle yüksekte olan kürek tarafında rotasyon varlığını saptar (Otman ve ark., 1998, Janicki ve Alman, 2007, Erbil, 2013, Exhibits, 2010).

\subsubsection{Omuz Seviyesi fark ölçüm testi}

Omuz yükseklik seviyelerini ölçmek için bireyden rahat pozisyonda ve bakışları karşıya doğru olacak şekilde durması istenir. Omuzda belirlenen noktalar arasındaki mesafe farkı ölçülür. Bu test yöntemiyle yüksekte kalan omuz tarafına doğru omurgalarda kayma varlığı saptanır (Otman ve ark., 1998, Exhibits, 2010).

\subsubsection{Kürek Kemiklerinin açılanma testi}

Omurgadaki açısal farkı değerlendirmek için omurga kemiklerinin omurganın ana çıkıntısı işaretlenir. Başın orta seviyesinden tutulan çekül ile omurganın kayma yaptığı yön tespit edilir. Bu test yöntemiyle omurganın dışa kayma yönü tespit edilir (Lin, 1985). 


\subsection{Arduino}

Arduino, algılayıcıların fiziksel ortamlardan aldıkları verilerin işlenmesi ve yorumlanması için kullanılan mikrodenetleyicili devre kartıdır. Bu kartın; dijital-analog pin sayısı, boyut ve mikrodenetleyici türüne göre farklı sürümleri bulunmaktadır. Arduino geliştirme kartının ilk kullanılan sürümü Arduino Uno'dur. Arduino Uno kartında 14 dijital ve 6 analog girişe sahip atmega328 mikrodenetleyicisi bulunmaktadır. Arduino kartlarında kullanılacak yazılım, Arduino IDE isimli açık kaynak yazılımı ile geliştirilmektedir. Arduino IDE yazılımı içerisinde basitleştirilmiş $\mathrm{C}++$ programlama dili kullanılmaktadır (Taşdelen, 2016).

\subsection{MPU-6050 İvme Ölçer}

MPU-6050 denge, konum ve açı verilerini kullanan projelerde kullanılan, Şekil 2'de verilen eksenli konum ve açısal ivmeölçere sahip algılayıcı kartıdır. Kart üzerindeki voltaj regülâtörü sayesinde 3 ile $5 \mathrm{~V}$ arası bir besleme voltajı ile çalışmaktadır. Algılayıcıdan gelen ivmeölçer ve XYZ verileri ayrı kanallardan $\mathrm{I}^{2} \mathrm{C}$ çıkışı vermektedir (Chang vd., 2016).

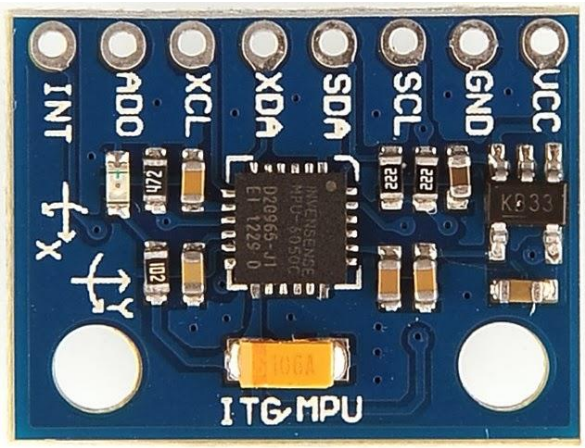

Şekil 2. MPU-6050 algılayıcısının görünümü.

\section{3. Ölçüm Cihazının Geliştirilmesi}

Bu çalışmada skolyoz hastalığının teşhisi için gerekli verilerin bulunmasını sağlayan bir cihaz geliştirilmiştir. Bu cihaz tasarımında Şekil 3'deki modelde görüldüğ̈̈ gibi jel pedlere sabitlenmiş 5 adet XYZ algılayıcısı kullanılmaktadır. Algılayıcıdan alınan veriler Arduino Uno geliştirme kartı üzerinde işlenmektedir. Skolyoz hastalığının teşhisi için kullanılacak verilerin çıkartılmasında 3 farklı ölçüm ve 9 farklı nokta kullanılmaktadır.

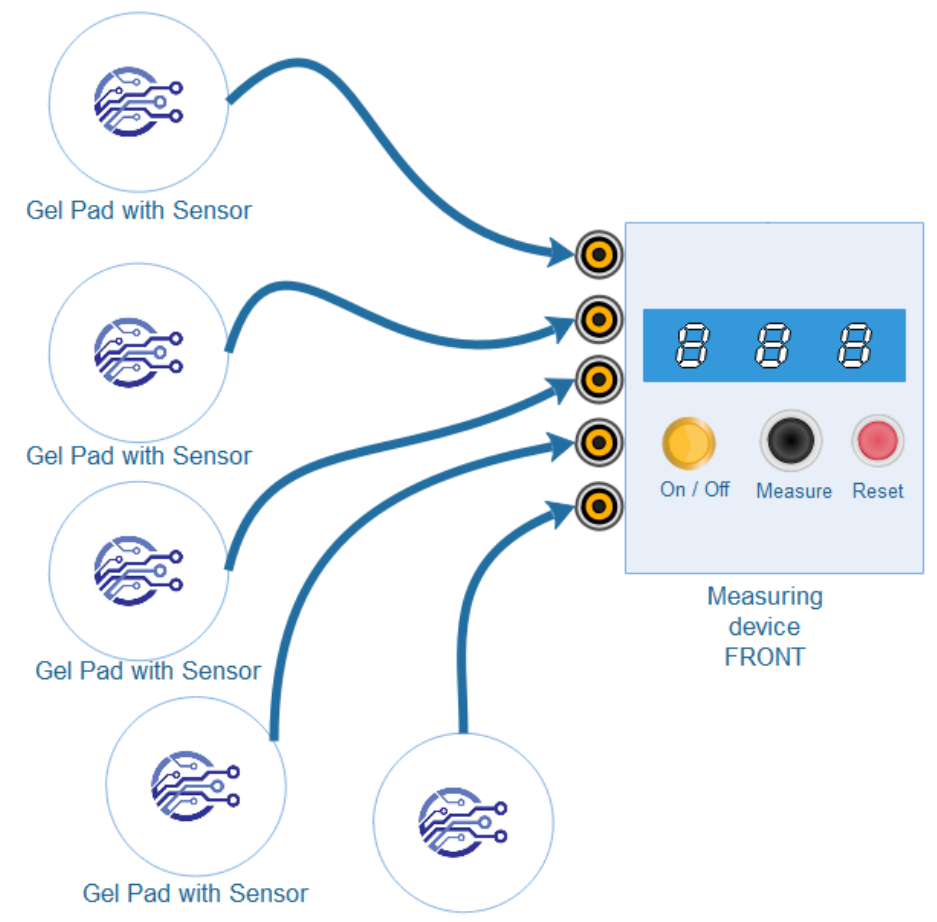

Gel Pad with Sensor

Şekil 3. Ölçüm Cihazının Tasarımı 


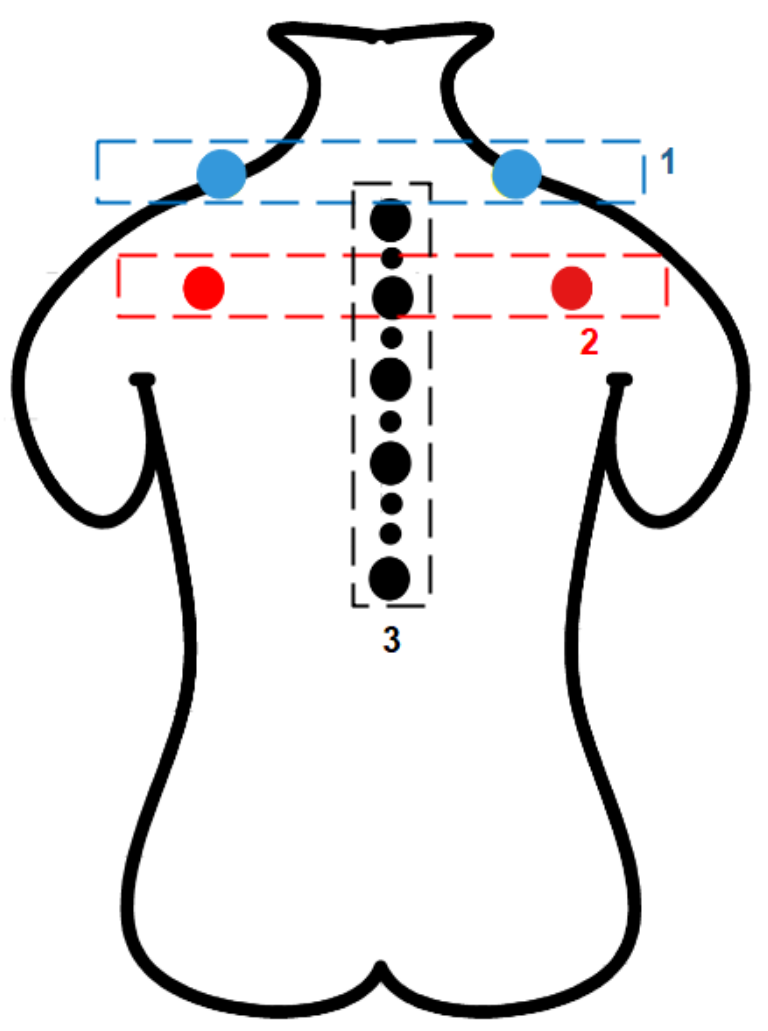

Şekil 4. Ölçüm yapılan noktalar

\subsection{Omuz Seviyesi Farkının Ölçülmesi}

Bu ölçümün yapılması için Şekil 4'de verilen 1 numaralı ölçüm noktalarına 2 tane algılayıcısı olan jel ped yapıştırılmaktadır. Şekil 5'de gösterilen omuz seviyeleri arasındaki farkın ölçülmesi için konum algılayıcısından gelen Y verileri kullanılmaktadır. Bu Y verilerin arasında oluşan fark Eş 1'de verildiği gibi, omuz seviyesi farkını temsil etmektedir. Sonuç olarak elde edilen fark, hangi omuzun yüksek olduğunun tespitine kullanılacaktır. Ayrıca skolyozun dış bükey yönünün bulunmasında kolaylık sağlayacaktır.

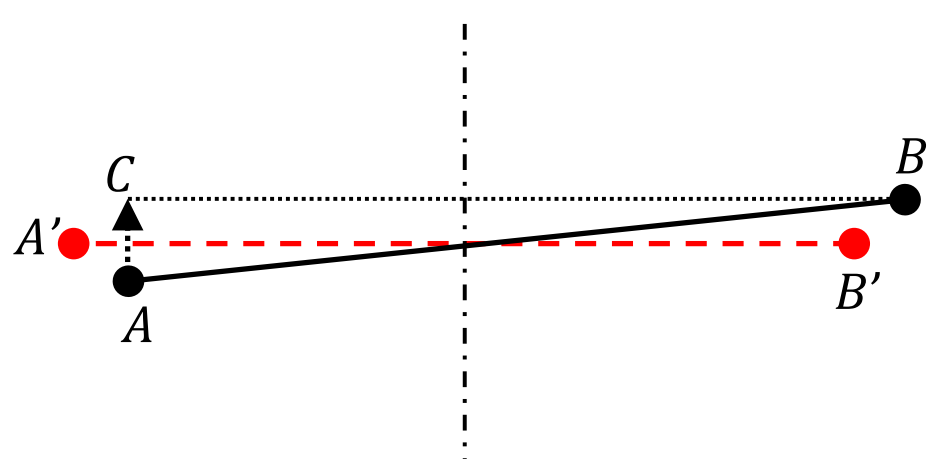

Şekil 5. Omuz seviyesi farklının çıkartılması

$$
|A C|=y_{b}-y_{a}
$$

\section{2. Öne Eğilme Testi ile Kürek Kemikleri Arası Açının Ölçülmesi}

Öne eğilme testi ile açı ölçümün yapılması için Şekil 4'de verilen 2 numaralı ölçüm noktalarına 2 tane algılayıcılı jel ped yapıştırılmaktadır. Şekil 6'de gösterilen kürek kemikleri arası açı farkının ölçülmesi için konum algılayıcısından gelen X ve Y verileri kullanılmaktadır. Eş. 2'de verilen formüle gelen veriler aktarılarak istenilen açı bulunmaktadır. Elde edilen açı ile skolyozun omurgalar üzerindeki rotasyonu belirlenmektedir. 


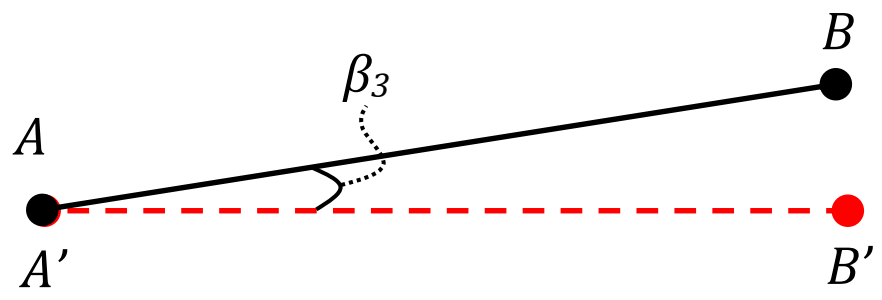

Şekil 6. 2 numaralı ölçüm noktasının skolyoz açısının çıkartılması

$$
\beta_{3}=\tan ^{-1}\left(\frac{y_{b}-y_{a}}{x_{b}-x_{a}}\right)
$$

\subsection{Omurganın Açılanma Derecelerinin Ölçümü}

Skolyoz hastalığının tespitinde gözlemlemede şüphelenilen referans noktalarına pedler yapıştırılmaktadır. Gerçekleştirilen cihazda doğru sonuç alınabilecek en iyi referans noktalar tercih edilmiştir. Bu ölçümün yapılması için Şekil 4'de verilen 3 numaralı ölçüm noktalarına 5 tane algılayıcısı olan jel ped yapıştırılmaktadır. Bu jel pedler bireyin omurgasının ana çıkıntısına yerleştirilmektedir. Algılayıcıdan gelen X ve Y verilerinin işlenmesi için gerekli formül Şekil 7'deki geometriksel gösterimden çıkartılmıştır. A-C, A-D, AE, B-D, B-E, C-E noktaları arasında istenilen açıların bulunması için Eş. 3 kullanılmaktadır. Bu eşitlik referans noktalarına ayrı ayrı uygulanmaktadır. Sonuç olarak referans noktalarda elde edilen açılar ile omurganın yana eğilme yönü ve derecesi bulunmaktadır. Ayrıca omuz seviyesi farkı ölçümünde bulunan dış bükey tespitinin kontrolünü sağlanacaktır.

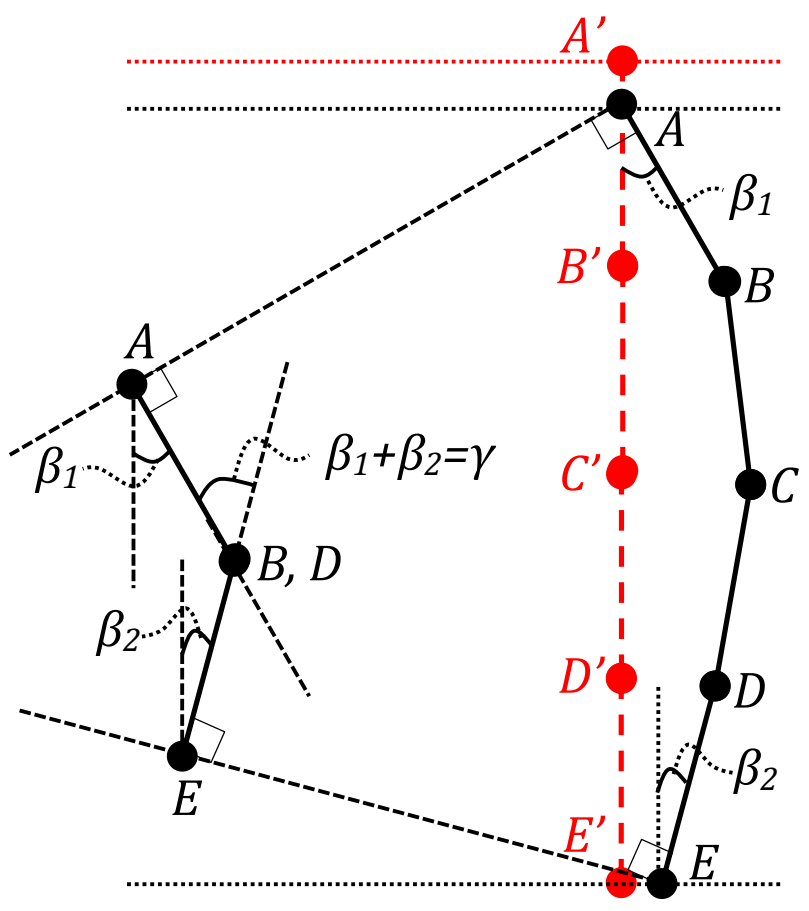

Şekil 7. 3 numaralı ölçüm noktasının skolyoz açısının çıkartılması

$$
\gamma=\tan ^{-1}\left[\frac{\left(\frac{x_{b}-x_{a}}{\left|y_{b}-y_{a}\right|}\right)+\left(\frac{x_{e}-x_{d}}{\left|y_{d}-y_{b}\right|}\right)}{1-\left(\frac{x_{b}-x_{a}}{\left|y_{b}-y_{a}\right|}\right)\left(\frac{x_{e}-x_{d}}{\left|y_{d}-y_{b}\right|}\right)}\right]
$$

\section{Deneysel Çalışma}

Tasarlanan cihaz 3 farklı bireyden alınan sonuçlar ile test edilmiştir. Her bireyde skolyoz hastalığının tespitinde kullanılacak 3 farklı ölçüm yapılmıştır. Alınan bu veriler Şekil 8'de verilmişstir. 


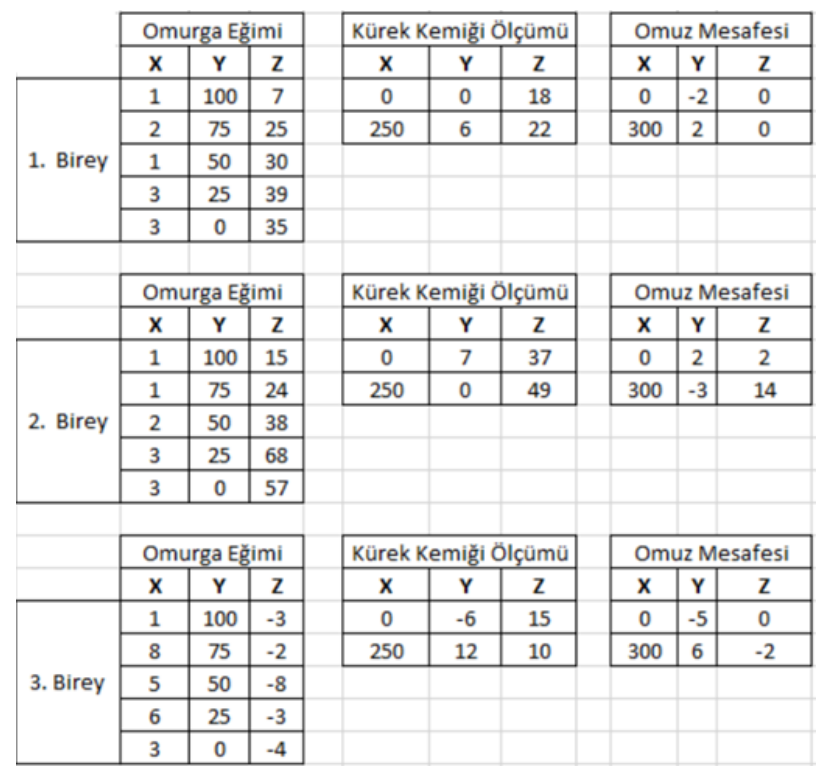

Şekil 8. Ölçüm Cihazından gelen veriler

Bireyler üzerinde uygulanan testlerden elde edilen ham verilerin formülleri ile işlenmesi sonucunda çıkan bilgiler Şekil 9'da grafiksel olarak gösterilmiştir.

Şekil 9 (a) 'da verilen grafikte 3 farklı kişinin omurganın açılanma dereceleri çıkartılmıştır. 1.bireyden elde edilen veriler 0 ile 4 derece arasına olduğu görülmektedir. Skolyoz hastalı̆̆ının varlı̆̆ında bahsedilmesi için radyolojik görüntülemede 10 derece ve üzeri olması gerekmektedir. Buna göre 1. bireyde skolyoz rastlanmamıştır. 2. bireyden elde edilen veriler 0 ile 2 derece arasındadır. Bu sonuca göre 2. bireyde de skolyoz rastlanmamıştır. 3. Bireyden elde edilen sonuçlara bakıldığında 2 ile 13 derece arasında olduğu görülmektedir. Buna göre 3. bireyde eğri açıklığı sola bakan skolyoz hastalığına rastlanmıştır.

Şekil 9 (b) 'de verilen grafikte 3 farklı kişinin öne eğilme testi ile kürek kemikleri arası dereceleri çıkartılmıştır. 1.bireyde gövde rotasyonu 1.375 derece, 2.bireyde 1.604 derece çıkmıştır. Bu sonuçlara göre bireylerin omurgalarında önemli bir rotasyon yoktur. 3.bireyin gövde rotasyonu 4.11 derece çıkmıştır. Buradan Şekil 9 (a) 'da çıkartılan skolyoz tanısına rotasyonunda eşlik ettiği sonucu çıkmaktadır.

Şekil 9 (c) 'de verilen grafikte 3 farklı kişinin omuz seviye farkının milimetre olarak sonucu çıkartılmıştır. 1.bireyde omuz yükseklik fark1 $4 \mathrm{~mm}$, 2.bireyde $5 \mathrm{~mm}$ çıkmıştır. Bu sonuca göre 1.ve 2.bireyin omuz seviyelerinde önemsenecek bir fark bulunmamaktadır. 3.birey de omuz yüksek farkı $11 \mathrm{~mm}$ çıkmaktadır. Buna göre sola bakan skolyoz açıklığının omuzlarda yükseklik farkına sebep olduğu görülmektedir.

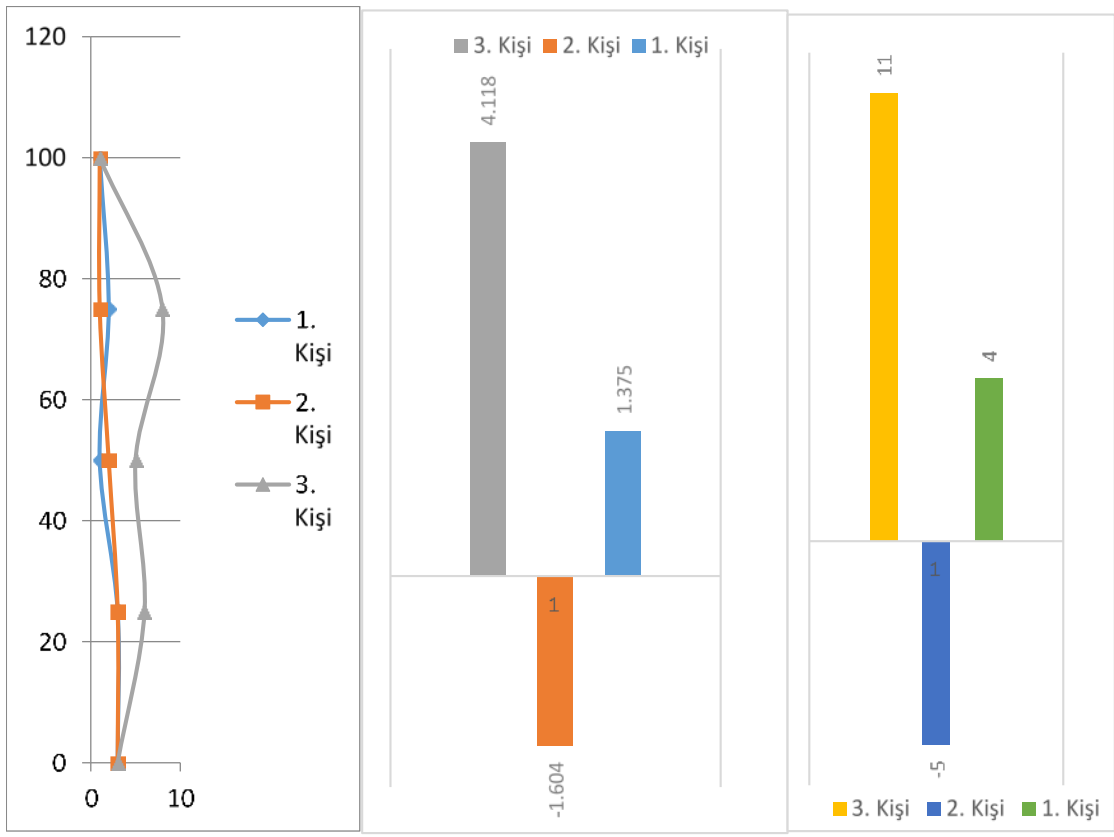

(a)

(b)

(c)

Şekil 9. (a) Omurganın açılanma dereceleri (b) öne eğilme testi ile scapulalar arası açı ölçümü ve (c) omuz seviye farkı ölçümü 


\section{Sonuç}

Skolyoz, hastalığın erken dönemlerinde eğitim almamış kişilerce tespit edilememektedir. Genellikle bu hastalık ileri aşamalarda fark edilmekte ve sağlık kuruluşlarına başvurulmaktadır. Skolyozun erken teşhisinde fiziksel testlerin uygulanması için uzman sağlık personeli gerekmektedir. Ölçüm esnasındaki kişisel hatalar ve farklı kişilerce yapılan ölçümler skolyozun tespit edilmesini etkilemektedir. Fiziksel testlerin uygulamasının zaman alması sebebiyle skolyoz, toplum sağlı̆̆ı taramaları kapsamına alınmamaktadır. Hastalığı tespitinde kullanılan Cobb açısını hesaplayabilmek için birey radyolojinin zararlı etkilerine maruz kalmaktadır.

Skolyoz hastalığının tanısında genel olarak subjektif yöntemler kullanılmaktadır. Bu yöntemlerde skolyoz hastalığının tanısı genel olarak gözleme dayalı işlemlerdir. Bununla birlikte çok yaygın olmasa da biyomekanik ve biyokimyasal algılayıcılarının kullanımı da bulunmaktadır.

Bu çalışmada erken teşhisi kolaylaştıracak, kullanım kolaylı̆̆ına sahip, radyoaktif etkileri olmayan ve maliyeti düşük bir skolyoz tespit cihazının tasarımına gerçekleştirilmiştir. Tasarlanan cihaz fiziksel testlerde kullanılan yöntemlerin tamamını gerçekleştirebilmektedir. Ölçümler sonucunda elde edilen ham veriler, geliştirilen eşitliklere uygulanarak istenilen sonuçlar elde edilmektedir. Bu sonuçlar uzmanlar tarafından değerlendirilerek bireyin hastalığı hakkında yorumlar yapılabilmektedir. 


\section{Kaynakça}

Chang, H. C., Hsu, Y. L., Yang, S. C., Lin, J. C., \& Wu, Z. H. (2016). A wearable inertial measurement system with complementary filter for gait analysis of patients with stroke or Parkinson's disease. IEEE Access, 4, 8442-8453.

Exhibits, E. (2010). Scoliosis Imaging : What Radiologists. Main, 30(2006), 1823-1842. https://doi.org/10.1148/rg.307105061

Janicki, J. A., Alman, B., Scoliosis: Review of diagnosis and treatment. Paediatric Child Health, 12(9), 771-776, 2007. Erişim Linki: https://www.ncbi.nlm.nih.gov/pmc/articles/PMC2532872/

Lin, L. I. (1985). Early Diagnosis of Scoliosis Based on School-Screening. Journal of Bone \& Joint Surgery, American Volume, 67(8), 1202-1205.

Erbil, O. (2013). "Review of Radiological Assessment and Classification Systems of Adolescent Idiopathic Scoliosis.” Türk Ortopedi ve Travmatoloji Birliği Derneği Dergisi 12(1):73-82. Retrieved (http://www.totbid.org.tr/files/ONLIB/13_1/12ErbilOguz.pdf).

Otman, A., S., Demirel H., Sade, A., (1998) Tedavi Hareketlerinde Temel Değerlendirme Prensipleri. 2. Baskı. Hacettepe Üniversitesi Fizik Tedavi ve Rehabilitasyon Yüksekokulu Yayınları.

Oxborrow, N. J., (2000). "Assessing the child with scoliosis: The role of surface topography”. Archives of Disease in Childhood, 83(5), 453-455. https://doi.org/10.1136/adc.83.5.453

Taşdelen, K., Şimşek, M., A., (2016) Arduino ile Tasarlanmış Sistemlerin İnternet Tabanlı Kontrolü ve İzlenmesi. SDU International Journal of Technological Science, 8(1).

Trobisch, P., Suess, O., Schwab, F., (2010) Idiopathic scoliosis. Deutsches Ärzteblatt International, 107(49), 875-883, https://doi.org/10.3238/arztebl.2010.0875

Yaman, O., Dalbayrak, S., (2014) Idiopathic scoliosis. Turkish Neurosurgery, 24(5), 646-657, https://doi.org/10.5137/10195149.JTN.8838-13.0

Yilmaz, H. G., Kuru, T., Yavuzer, G., (2012) Gövde Ortezi Kullanan İdiyopatik Skolyozlu Adolesanlarda Bad Sobernheim Stres Sorgulama Formunun Türkçe Adaptasyonu ve Güvenirliği. Turkiye Fiziksel Tip ve Rehabilitasyon Dergisi, 58(3), 225-228, https://doi.org/10.4274/tftr.33600 